\title{
DECISIVE INFLUENCE OF ENVIRONMENT ON AROMATIC/AROMATIC INTERACTION GEOMETRIES. COMPARISON OF AROMATIC/AROMATIC INTERACTIONS IN CRYSTAL STRUCTURES OF SMALL MOLECULES AND IN PROTEIN STRUCTURES
}

\author{
Jelena M. Živković, ${ }^{a}$ Ivana M. Stanković, ${ }^{b}$ Dragan B. Ninković, ${ }^{a}$ and Snežana D. Zarić*c \\ ${ }^{a}$ Innovation center of the Faculty of Chemistry, Studentski trg 12-16, 11000 Belgrade, \\ Serbia \\ ${ }^{b}$ Institute of Chemistry, Technology and Metallurgy, University of Belgrade, Njegoševa \\ 12, 11000 Belgrade, Serbia \\ ${ }^{c}$ Faculty of Chemistry, University of Belgrade, Studentski trg 12-16, Belgrade, 11000, \\ Serbia
}

\section{Methodology}

The CSD and PDB search

The Cambridge Structural Database (CSD, November 2018, version 5.40) was searched for benzene/benzene, toluene/toluene and p-phenol/p-phenol interactions using the same criteria as described in our previous work. ${ }^{1}$ The CSD search program ConQuest ${ }^{2}$ was used to retrieve structures satisfying the following criteria: (a) the crystallographic $\mathrm{R}$ factor $<10 \%$, (b) error-free coordinates according to the criteria used in the CSD, (c) the H-atom positions were normalized using the CSD default bond lengths, (d) no polymer structures, (e) no powder structures, (f) no disordered structures, (g) 3D coordinates determined.

The Protein Data Bank (PDB, the $28^{\text {th }}$ of June 2019) was searched for interactions of similar aromatic groups phenylalanine/phenylalanine (Phe/Phe) and tyrosine/tyrosine (Tyr/Tyr). The search was done by employing the following criteria, (1) only crystal structures with a resolution of $1.5 \AA$ or better were accepted; (2) only crystal structures with $\mathrm{R}_{\text {free }}-\mathrm{R}_{\text {work }} \leq$ 0.05 were accepted; (3) only crystal structures with sequence identity $<30 \%$ were taken in order to assure the nonredundancy; (4) a residue is not considered if it does not contain all heavy atoms resolved crystallographically; (5) a residue is not considered if it has too short nonbonding contact (overlap of the van der Waals spheres $\geq 0.4 \AA$ with nonbonded atoms); (6) a residue is not considered if its side chain rotamer is disfavoured; (7) a contact is not considered if there are any foreign atoms (atoms that do not pertain to the aromatic rings studied) within the sphere of center-center distance diameter in order to analyse only the direct interactions between the two rings. If not already present, polar hydrogen atom of the $-\mathrm{OH}$ group in Tyr, coordinates were determined using the program REDUCE under 
PHENIX package. ${ }^{3}$ Scripts for the search were written in Python, ${ }^{4}$ and for PDB file parsing MDAnalysis ${ }^{5}$ python library was used. Using these criteria we found aromatic/aromatic interactions in 3489 structures.

\section{Results from CSD search}

Table SI 1. The number of interactions obtained in the CSD (benzene/benzene, toluene/toluene and pphenol/p-phenol) and PDB (Phe/Phe and Tyr/Tyr) search, for each investigated system.

\begin{tabular}{|c|c|c|}
\hline System & Scheme & № interactions \\
\hline benzene/benzene & & 6911 \\
\hline toluene/toluene & & 3374 \\
\hline p-phenol/p-phenol & & 10268 \\
\hline Phe/Phe & & 6435 \\
\hline Tyr/Tyr & & 2777 \\
\hline
\end{tabular}

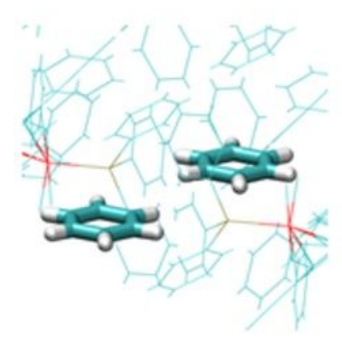

(a)

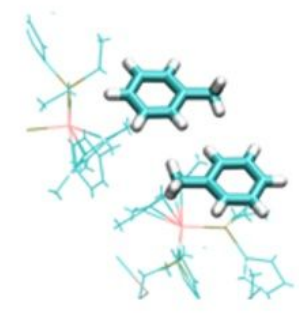

(b)

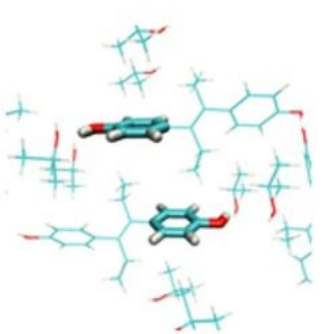

(c)

Figure SI 1. Examples of the parallel interactions of (a) benzene/benzene (CSD refcode CIGVIY, $\mathrm{P}_{1} / \mathrm{P}_{2}=$ $0.0^{\circ}, \mathrm{r}=5.2 \AA, \mathrm{R}=2.2 \AA$ ), (b) toluene/toluene (CSD refcode HADKOO, $\mathrm{P} 1 / \mathrm{P} 2=0.0^{\circ} \mathrm{r}=7.0 \AA, \mathrm{R}=0.4 \AA$ ) and (c) p-phenol/p-phenol (CSD refcode XEHPAB, $\mathrm{r}=1.9 \AA, \mathrm{R}=6.2 \AA, \mathrm{P} 1 / \mathrm{P} 2=0.0^{\circ}$ ) 


\section{Calculations}

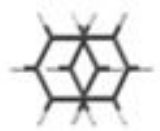

A

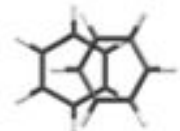

B

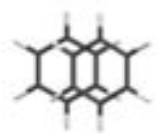

C

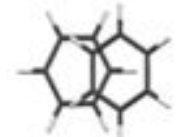

D

Figure SI 2. Four orientations (A, B, C and D) of benzene/benzene dimers used for calculations. ${ }^{6}$

Table SI 2. Calculated interaction energies $(\mathrm{kcal} / \mathrm{mol})$ at minima of potential curves for different $\mathrm{P}_{1} / \mathrm{P}_{2}$ angles $\left(^{\circ}\right)$ for A, B, C and D orientations (Figure SI 1 ). ${ }^{6}$

\begin{tabular}{|c|c|c|c|c|c|}
\hline $\begin{array}{c}\text { P1/P2 } \\
\text { angle }\end{array}$ & $\begin{array}{c}\text { offset } \boldsymbol{r} \\
(\mathbf{\AA})\end{array}$ & $\mathbf{A}$ & $\mathbf{B}$ & $\mathbf{C}$ & $\mathbf{D}$ \\
\hline $\mathbf{0}^{\circ}$ & 1.5 & -2.84 & -2.85 & -2.84 & -2.85 \\
\hline $\mathbf{2 0}^{\circ}$ & 1.5 & -2.72 & -2.73 & -2.64 & -2.64 \\
\hline \multirow{2}{*}{$\mathbf{4 0}^{\circ}$} & 1.0 & $/$ & $/$ & -2.45 & -2.45 \\
\cline { 2 - 6 } & 1.5 & -2.89 & -2.90 & $/$ & $/$ \\
\hline $\mathbf{6 0}^{\circ}$ & 1.0 & -3.02 & -3.02 & -2.48 & -2.49 \\
\hline $\mathbf{9 0}^{\circ}$ & 0 & -3.02 & -3.02 & -2.56 & -2.57 \\
\hline
\end{tabular}

Table SI 3. Calculated interaction energies $(\mathrm{kcal} / \mathrm{mol})$ at large offsets of potential curves for different $\mathrm{P}_{1} / \mathrm{P}_{2}$ angles $\left({ }^{\circ}\right)$ for A, B, C and D orientations (Figure SI1). ${ }^{6}$

\begin{tabular}{|c|c|c|c|c|c|}
\hline $\begin{array}{c}\text { P1/P2 } \\
\text { angle }\end{array}$ & $\begin{array}{c}\text { offset } \boldsymbol{r} \\
(\mathbf{\AA})\end{array}$ & $\mathbf{A}$ & $\mathbf{B}$ & $\mathbf{C}$ & $\mathbf{D}$ \\
\hline \multirow{2}{*}{$\mathbf{0}^{\circ}$} & 3.5 & -2.16 & -2.08 & -2.01 & -2.08 \\
\cline { 2 - 6 } & 4.5 & -1.89 & -1.97 & -2 & -1.97 \\
\hline \multirow{2}{*}{$\mathbf{0}^{\circ}$} & 3.5 & -2.04 & -2.05 & -2.04 & -2.06 \\
\cline { 2 - 6 } & 4.5 & -1.72 & -1.83 & -1.94 & -2.01 \\
\hline \multirow{2}{*}{$\mathbf{4 0}^{\circ}$} & 3.5 & -1.85 & -1.88 & -2.09 & -2.13 \\
\cline { 2 - 6 } & 4.5 & -1.37 & -1.5 & -1.61 & -1.78 \\
\hline \multirow{2}{*}{$\mathbf{0 0}^{\circ}$} & 3.5 & -1.44 & -1.49 & -1.7 & -1.84 \\
\cline { 2 - 6 } & 4.5 & -0.88 & -1.02 & -1.06 & -1.22 \\
\hline $\mathbf{9 0}^{\circ}$ & 3.5 & -0.63 & -0.78 & -0.8 & -0.93 \\
\hline
\end{tabular}

${ }^{a}$ The interaction energies at offset $4.5 \AA$ for the tilt angle of $90^{\circ}$ are omitted because the donor and acceptor molecules swap the roles. 


\section{Results from PDB search}

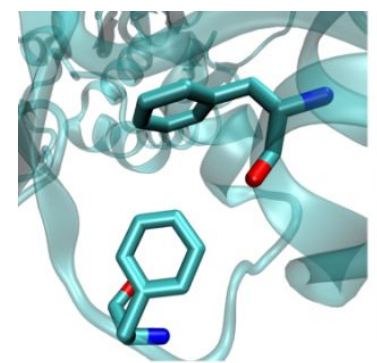

(a)

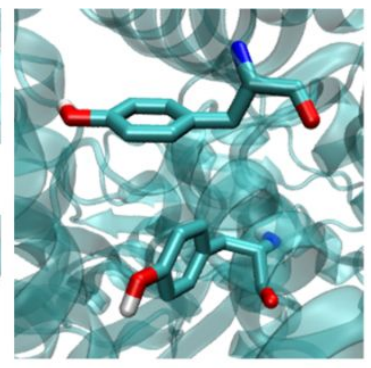

(b)

Figure SI 3. Examples of the most frequent interactions of (a) Phe/Phe (PDBid $2 \mathrm{HEU}, \mathrm{P}_{1} / \mathrm{P}_{2}=88.7^{\circ}$ ) and (b) Tyr/Tyr (PDBid 3V5R, $\left.\mathrm{P}_{1} / \mathrm{P}_{2}=89.4^{\circ}\right)$.

1Živković J. M.; Stanković I. M.; Ninković D. B.; Zarić S. D.; Phenol and toluene stacking interactions, including interactions at large horizontal displacements. Study of crystal structures and calculation of potential energy surfaces. Cryst. Growth Des., 2020, 20, 1025-1034.

${ }^{2}$ Bruno I.J.; Cole J. C.; Edgington P. R.; Kessler M.; Macrae C. F.; McCabe P.; Pearson J.; Taylor R.; New software for searching the Cambridge Structural Database and visualizing crystal structures. ActaCrystallogr.Sect B, 2002, 58, 389-397.

${ }^{3}$ Word J.M.; Lovell S.C.; Richardson J.S.; Richardson D.C.; Asparagine and glutamine: using hydrogen atom contacts in the choice of side-chain amide orientation, J.Mol. Biol.,1999, 285,1735-1747.

${ }^{4} \mathrm{http}: / /$ www.python.org

${ }^{5}$ Michaud-Agrawal N.; Denning E.J.; Woolf T.B.; Beckstein O.; MDAnalysis: A toolkit for the analysis of molecular dynamics simulations. J. Comput. Chem., 2011,32, 2319-2327.

${ }^{6}$ Ninković D. B.; Andrić J. M.; Malkov S. N.; Zarić S. D.; What are the preferred horizontal displacements of aromatic-aromatic interactions in proteins? Comparison with the calculated benzene-benzene potential energy surface. Phys ChemChem Phys, 2014, 16, 11173-11177. 